\title{
Enhanced cyclooxygenase-2 activity leads to intestinal dysmotility following hemorrhagic $\operatorname{shock}^{1}$
}

\author{
Yu-Ping Zhang ${ }^{\mathrm{I}}$, Xiu-Qing Hao', Li-Min Zhang ${ }^{\mathrm{III}}$, Ya-Ting Tian ${ }^{\mathrm{IV}}$ \\ DOI: http://dx.doi.org/10.1590/S0102-865020150120000008
}

${ }^{I}$ Master, Associate Professor, Institute of Microcirculation, Hebei North University, Zhangjiakou, China. Design of the study, acquisition of data, manuscript writing, critical revision.

I'Master, Department of Pathology, First Affiliated Hospital of Hebei North University, Zhangjiakou, China. Histopathological examinations, acquisition of data, statistics analysis.

IIIMaster, Assistant Researcher, Institute of Microcirculation, Hebei North University, Zhangjiakou, China. Acquisition of data, analysis and interpretation of data.

${ }^{\text {IV }}$ Master, School of Basic Medical Sciences, Hebei North University, Zhangjiakou, China. Acquisition of data.

\begin{abstract}
PURPOSE: To test whether hemorrhagic shock (HS) increases the Cyclooxygenase-2 (COX-2) expression in the intestine and whether this enhanced COX-2 expression mediates the intestinal dysmotility after HS.

METHODS: Male Wistar rats were randomly divided into HS sham group and HS group. At 180 min following HS establishment, the duodenum samples were harvested to assess the motility function, protein expression of COX-2 and the downstream products of COX-2, prostaglandins

RESULTS: Examination of motility function ex vivo showed that the contractile response to acetylcholine of smooth muscle strips of rats subjected to HS was significantly suppressed. A COX-2 inhibitor, NS-398, abolished this depressed contractile response after HS. Western blotting revealed an increased protein expression of COX2 in intestinal tissues of HS rats. Immunohistochemical examination indicated that intestine tissues of HS rats were manifested by part of villous expansion and disruption, a large amount of COX-2 positive cells appearance in lamina propria and submucosa. Furthermore, the contents of prostaglandin $\mathrm{E}_{2}$ was significantly increased in intestinal tissues of HS rats.
\end{abstract}

CONCLUSION: The enhanced COX-2/ prostaglandin $\mathrm{E}_{2}$ involves in the hemorrhagic shock induced intestinal dysmotility.

Key words: Shock, Hemorrhagic. Cyclooxygenase 2. Dinoprostone. Rats. 


\section{Introduction}

Motility disturbance of intestinal tract occurs frequently after insults of hemorrhagic shock (HS), severe sepsis, major operation and other critical conditions, which remains one of the most perplexing problems in critical care medicine. This complication may lead to functional ileus, prolonged hospitalization, increased medical costs, and even death ${ }^{1,2}$. Nevertheless, there remains no effective medical treatment for this intestinal dysfunction and the precise mechanisms underlying the intestinal dysmotility have not been fully elucidated.

Cyclooxygenase $(\mathrm{COX})$ is a rate-limiting enzyme of the synthesis of prostaglandins (PGs), which exerts important roles in cell proliferation, inflammatory cascade and smooth muscle function $^{3}$. COX-2 is an inducible form of the enzyme produced in a variety of stress conditions, such as sepsis ${ }^{4}$, tumor ${ }^{5}$, operative manipulation $^{6}$ and bowel obstruction ${ }^{7}$. Recent studies indicate that inducible expression of COX-2 in endotoxemia rats induces the motility disturbance of intestine ${ }^{8,9}$. Conversely, suppression of COX-2 using inhibitor of mitogen activated protein kinase attenuates the intestinal dysmotility ${ }^{8,9}$. These findings suggest that COX-2 is associated with the development of the intestinal dysmotility induced by endotoxin. The previous studies have found that HS can elicit intestinal dysmotility that involves increased inflammatory factors such as TNF- $\alpha$, IL-6 and iNOS/ $\mathrm{NO}^{10,11}$. These results prompted us to hypothesize that HS also increases the COX-2 expression and activity in the intestine and the enhanced COX-2 activity will contribute to the intestinal dysmotility after HS. To test this hypothesis, we conducted the measurement of ex vivo motility function to determine the ameliorating effect of COX-2 inhibition on motility function of intestinal muscle strips from HS rats. We also employed western blotting assay, immunohistochemical staining and the ELISA method to confirm the enhancing action of HS on the expression of COX-2 as well as downstream prostaglandins derived from COX2 in intestinal tissues.

\section{Methods}

\section{Experimental design and HS protocol}

The animal experiments were approved by the Animal Care Committee of Hebei North University and conformed to guidelines of National Institutes of Health. All efforts have been made to minimize animal suffering.
Male Wistar rats weighing 250 to $350 \mathrm{~g}$ were purchased from the Laboratory Animal Centre of Chinese Academy of Military Sciences (SCXK 2007-004) and were randomly divided into sham and HS groups. All the rats were fasted with ad libitum access to tap water for $12 \mathrm{~h}$ before the experiment procedures, and.

After rats anesthetized with pentobarbital sodium (50 $\mathrm{mg} / \mathrm{kg}$ ), bilateral femoral arteries and the right femoral vein were isolated. The right femoral vein was cannulated for the administration of heparin sodium (500 U/kg). The right femoral artery was cannulated with a polyethylene tubing containing heparinized saline (10 units/cc), and then connected to a blood pressure transducer (YP100, Chengdu Instrument, China) for monitoring blood pressure continuously during the shock period. Another catheter was inserted into the left femoral artery for bleeding. After a 30-min equilibrium, blood was withdrawn from the left femoral artery in HS group rats to produce a mean arterial pressure (MAP) of $40 \pm 2 \mathrm{mmHg}$ within $10 \mathrm{~min}$. MAP was maintained at this level for $180 \mathrm{~min}$ by withdrawing or reinfusion blood as required. In the sham group, rats were anesthetized and cannulated as described above, but no blood was removed. The duodenum samples were harvested at $180 \mathrm{~min}$ of hypotension in HS group of rats $(n=6)$ and at corresponding time point in sham group of rats $(n=6)$ for the following experiments.

\section{Intestinal motility measurement}

Segments of rat duodenum were excised, washed, freed from mesenteric attachment, and cut into smaller pieces with 1 $\mathrm{cm}$ in length. Whole thickness muscle strips $(10 \mathrm{~mm}$ long and $5 \mathrm{~mm}$ wide) were suspended along longitudinal smooth muscle orientation in a thermo-controlled $\left(37^{\circ} \mathrm{C}\right)$ organ bath containing Krebs solution and continuously bubbled with $95 \% \mathrm{O}_{2}$ and $5 \% \mathrm{CO}_{2}$. One end of the muscle strip was pinned to the tissue holder and the other was attached to an isometric force transducer $(\mathrm{JZJ} 01 \mathrm{H}$, Chengdu Instrument, China). It was then stretched passively to an initial tension of $1.0 \mathrm{~g}$. Before testing, muscle strips were allowed to equilibrate in Krebs solution for $30 \mathrm{~min}$. During the whole experiment, the Krebs solution was changed every $20 \mathrm{~min}$. Acetylcholine (Ach, $0.1 \mathrm{mM}$ ) induced contractile response was determined to assess the function of intestinal motility. In sham group, sham muscle strips were incubated with Krebs solution plus vehicle for $15 \mathrm{~min}$. In shock group, muscle strips were incubated with Krebs solution plus vehicle. In shock + NS-398 group, shock muscle strips treated by Krebs solution plus NS-398 (sigma USA, $0.01 \mathrm{mM}$ ) for $15 \mathrm{~min}$. Contractions between different muscle strips of duodenum were normalized and calculated by converting 
grams of contraction to grams per square millimeter per section of tissue ${ }^{8-10}$.

\section{Western blotting}

Duodenum samples were homogenized in a lysis buffer containing $50 \mathrm{Mm}$ Tris ( $\mathrm{pH} 7.4$ ), $150 \mathrm{mM} \mathrm{NaCl}, 50 \mathrm{mM} \mathrm{NaF}, 1$ mM EDTA, 1\% Triton X-100, 1\% sodium deoxycholate, $0.1 \%$ SDS. The homogenates were centrifuged at $12.000 \times \mathrm{g}$ for 10 $\min$ at $4^{\circ} \mathrm{C}$ and protein aliquots were stored at $-70^{\circ} \mathrm{C}$. The protein concentration of each sample was measured using bicinchoninic acid assay. Equal amounts of protein $(50 \mu \mathrm{g}$ per lane) were loaded and separated by electrophoresis using $10 \%$ sodium dodecylsulfatepolyacrylamide gel, then transferred to polyvinylidene fluoride membranes. Membranes were blocked with 5\% skimmed milk powder for $1.5 \mathrm{~h}$ and then incubated overnight at $4{ }^{\circ} \mathrm{C}$ in primary antibody for COX-2 (1:200 concentration) and $\beta$-actin (1:2000 concentration). The membranes were then washed twice and incubated with a horseradish peroxidase conjugated anti-rabbit IgG secondary antibody at room temperature for $1.5 \mathrm{~h}$. Luminescence was detected using a chemiluminescent kit for antibody detection. The relative density of COX-2 to $\beta$-actin band was calculated and used to assess the expression of COX-2.

\section{Immunohistochemistry}

Duodenum samples were harvested, fixed in $4 \%$ paraformaldehyde, dehydrated by gradient ethanol, embedded in paraffin and cut in $4 \mu \mathrm{m}$ thick sections. Sections were deparaffined at $60^{\circ} \mathrm{C}$ for $30 \mathrm{~min}$, dehydrated in gradient ethanol and conducted antigen retrieval by heating for $10 \mathrm{~min}$. Sections were incubated at $4^{\circ} \mathrm{C}$ overnight with primary antibody for COX-2 (1:400 concentration), which was the same as that used in the western blot assay. Sections were washed twice by phosphate buffer solution and incubated with a horseradish peroxidase conjugated anti-rabbit IgG secondary antibody at $37^{\circ} \mathrm{C}$ for $30 \mathrm{~min}$. Antibody localizations on samples were visualized with 3,3'-diaminobenzidine. In control experiments, the PBS was substituted for COX-2.

\section{ELISA assay}

Samples of duodenum were harvested from sham and HS rats, and then homogenized in normal saline at a ratio of 9 $\mathrm{mL}$ per $1 \mathrm{~g}$ of tissue. The tissue homogenate was centrifuged for $10 \mathrm{~min}$ at $3000 \mathrm{rpm}$ at $4^{\circ} \mathrm{C}$. The supernatant fluid was stored at $-70^{\circ} \mathrm{C}$ for the next assay. The contents of thromboxane $\mathrm{A}_{2}\left(\mathrm{TX} \mathrm{A}_{2}\right)$, prostaglandin $(\mathrm{PG}) \mathrm{E}_{2}, \mathrm{PG} \mathrm{F}_{2 \mathrm{a}}$ and $\mathrm{PG} \mathrm{I}_{2}$ in supernatant fluid of duodenum tissues were measured by commercial available kits (abcam USA). The total protein concentration of supernatant fluid was measured using bicinchoninic acid assay. The contents of TX $\mathrm{A}_{2}, \mathrm{PG} \mathrm{E}_{2}, \mathrm{PG} \mathrm{F}_{2 \mathrm{a}}$ and $\mathrm{PG} \mathrm{I}_{2}$ were calibrated using the concentration of total protein and expressed as $\mathrm{ug} / \mathrm{g}$ protein.

\section{Statistical analysis}

Results are expressed as mean $\pm \mathrm{SD}$. Statistical analysis was performed using SPSS 18.0 by one-way analysis of variance (ANOVA) for comparison of multiple groups and independentsample $T$ test for comparison of two groups. $P$ values less than 0.05 were considered statistically significant.

\section{Results}

\section{Effect of COX-2 on intestinal motility of rats sub- jected to HS ex vivo}

Examination of intestinal motility ex vivo indicated that the Ach-induced contractile response of smooth muscle strips isolated from duodenum of HS rats was significantly suppressed. Compared with that of sham muscle strips, the $0.1 \mathrm{mM} \mathrm{Ach}$ evoked contractile response dropped by nearly $60 \%$ in HS muscle strips $\left(0.98 \pm 0.14\right.$ vs $\left.0.42 \pm 0.13 \mathrm{Grams} / \mathrm{mm}^{2} \cdot \mathrm{S}, \mathrm{p}<0.01\right)$. NS-398, a COX-2 inhibitor, significantly increased the contractile response of smooth muscle strips suppressed by the insult of HS $(0.60 \pm 0.13$ Grams $\left./ \mathrm{mm}^{2} \cdot \mathrm{S}, \mathrm{p}<0.05\right)$, but increased contractile response was still lower than that of sham group $(\mathrm{p}<0.01$, Figure 1$)$.

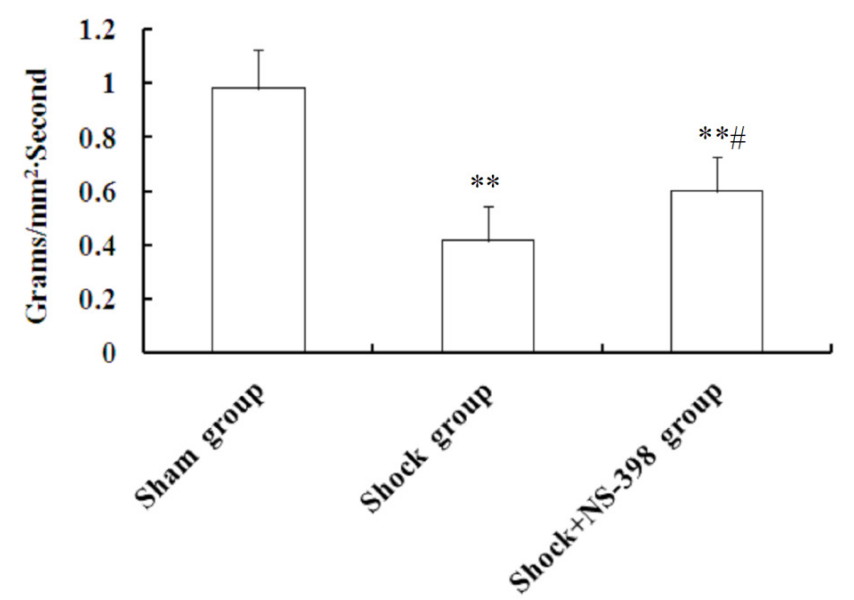

FIGURE 1 - The influence of Cyclooxygenase-2 inhibitor on the motility of intestine harvested from hemorrhagic shock rats.

Contractile response to acetylcholine of intestine harvested from hemorrhagic shock rats decreased significantly compared with that of sham rats $(p<0.01)$; Contractile response was elevated by Cyclooxygenase-2 inhibitor NS-398 significantly $(\mathrm{p}<0.05)$, but still decreased compared with that of sham rats $(\mathrm{p}<0.01)$. 


\section{Protein expression of $C O X-2$ in intestinal tissues of rats subjected to $H S$}

Western blotting assay was applied to determine whether expression of COX-2 protein was upregulated in intestine after HS. Results indicated that the expression of COX-2 protein of intestinal tissues in shock group was dramatically increased when compared with that in sham group (Figure 2). To determine the source of COX-2 expression, immunohistochemical examination was conducted in the full-thickness intestine. The results showed that the intestinal tissues of sham group were characterized by a normal architecture and quite rare or none of COX-2 positive cells (stained brown Figure 3A). In contrast, the intestine of shock group was manifested by part of villous expansion and disruption, a large amount of Cyclooxygenase- 2 positive cells appearance in lamina propria and submucosa (Figure $3 \mathrm{~B}$ ). The COX-2 positive cells were resident plasmacytes, infiltrating leukocytes and part of myenteric neurons.
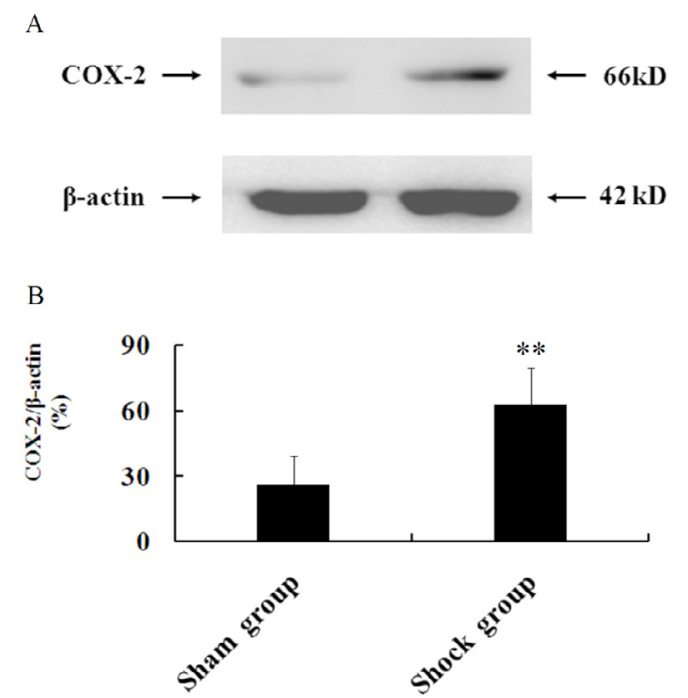

FIGURE 2 - The expression of Cyclooxygenase-2 in intestinal tissue following hemorrhagic shock measured by western blotting.

Compared with that of sham group, the protein expression of Cyclooxygenase-2 increased significantly in intestinal tissues of shock group $(\mathrm{p}<0.01)$.
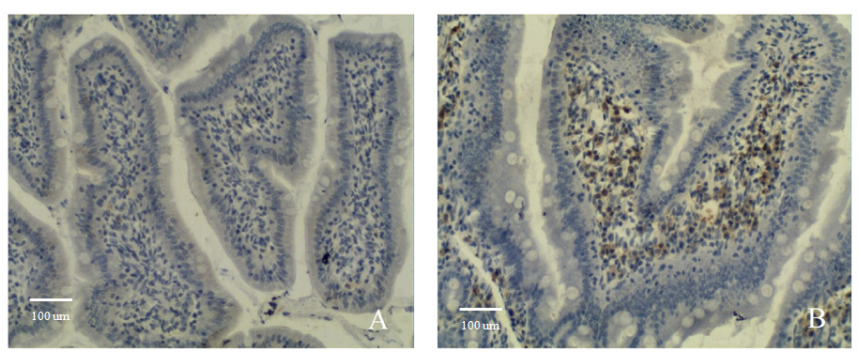

FIGURE 3 - The expression of Cyclooxygenase-2 in intestinal tissue following hemorrhagic shock measured by immunohistochemistry. A. The intestinal tissues of sham group had normal architecture, quite rare Cyclooxygenase-2 positive cells (stained brown). B. The intestinal tissues of shock group were manifested by part of villous expansion and disruption, Cyclooxygenase-2 positive cells appearance in lamina propria and submucosa.

\section{Changes of prostaglandins in intestine of rats sub- jected to $H S$}

Results from ELISA assay showed that there were no significant differences in contents of TX $\mathrm{A}_{2}, \mathrm{PG} \mathrm{F}_{2 \mathrm{a}}$ and PG $\mathrm{I}_{2}$ between sham and shock group ( $p>0.05)$. In contrast, contents of prostaglandin $\mathrm{E}_{2}$ were significantly increased in intestinal tissues of shock group $(21.2 \pm 5.8$ vs $45.9 \pm 14.7 \mathrm{ug} / \mathrm{g}$ protein, $p<0.01$, Figure 4).
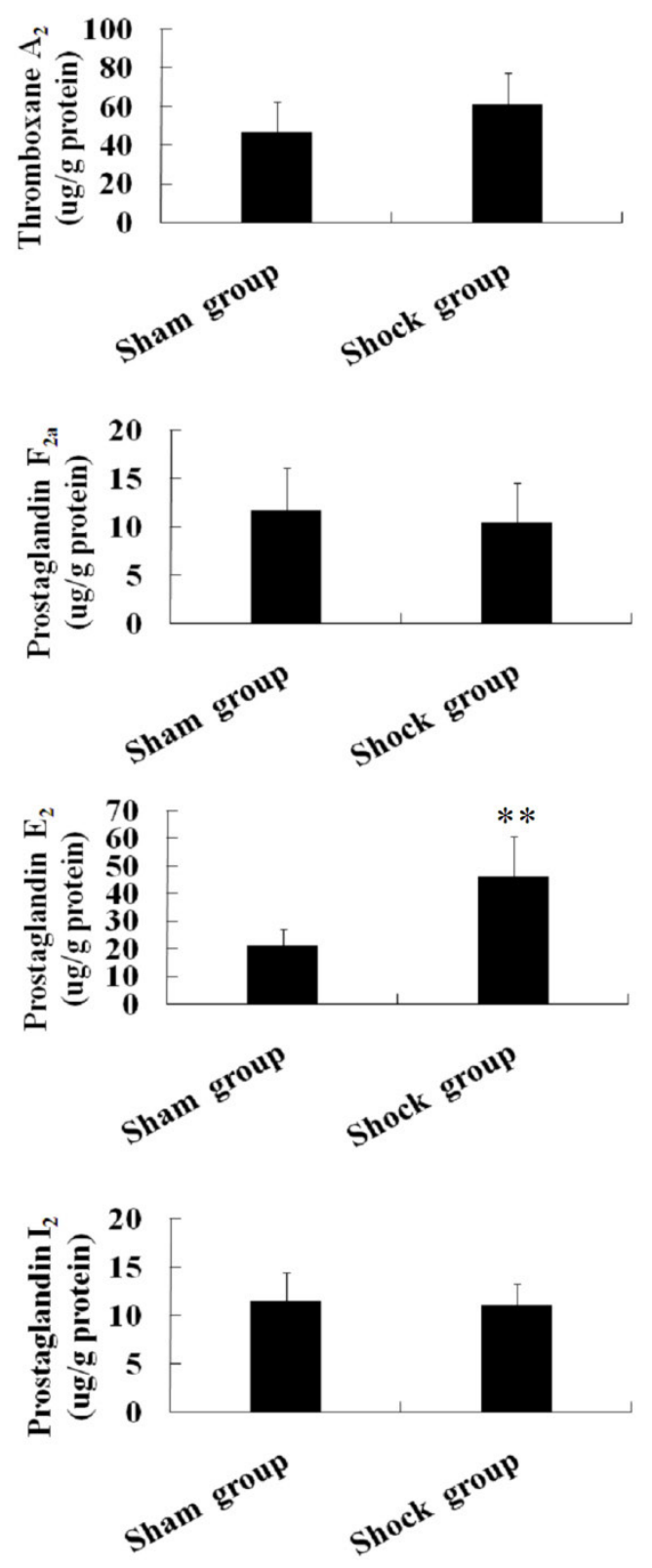

FIGURE 4 - The changes of prostaglandins content in intestinal tissues after hemorrhagic shock.

There were no significant differences in contents of thromboxane $\mathrm{A}_{2}\left(\mathrm{TX}_{2}\right)$, prostaglandin (PG) $\mathrm{F}_{2 \mathrm{a}}$ and $\mathrm{PG} \mathrm{I}_{2}$ between sham and shock group ( $\left.\mathrm{p}>0.05\right)$. Compared with those of sham group, contents of $\mathrm{PG}_{2}$ increased significantly in intestinal tissues of shock group $(\mathrm{p}<0.01)$. 


\section{Discussion}

Critical conditions such as trauma, hemorrhage and sepsis are commonly associated with intestinal dysmotility that lead to postinjury atony and functional ileus. The present study investigated the involvement of COX-2 activation in the intestinal dysmotility induced by HS. We found that HS significantly suppressed the motility function of the intestine, which was accompanied by increased protein expression of COX-2 and elevated level of $\mathrm{PG} \mathrm{E}_{2}$ Inhibition of COX-2 reversed this intestinal dysmotility. These results indicated that increased COX-2 activity produced by HS leads to intestinal dysmotility that increase the vulnerability to the development of multiple organ dysfunction syndrome and ultimately resulting in the increase of mortality.

It has been shown that in a rat model of bowel obstruction, the COX-2 expression is increased in colon oral to obstruction. Especially, the upregulation of COX-2 occurs in the circular and longitudinal smooth muscle cells ${ }^{12}$. Another study revealed that intestinal operative manipulation upregulates the COX-2 expression in resident macrophages and recruited monocytes of gut and that PGs derived from the COX-2 is involved in the occurrence of postoperative ileus ${ }^{13}$. Moreover, using a rat model of dextran sodium sulfate induced acute intestinal injury, Fukata ${ }^{14}$ demonstrated that the COX-2 expression is upregulated mainly in intestinal epithelial cells via a TLR4- and MyD88- dependent mechanism. These findings suggest that the COX-2 is a critical contributor to the intestinal dysmotility induced by different classes of injuries. The present study extends these previous studies by showing that the COX-2 expression in the intestine was significantly enhanced following $\mathrm{HS}$ and that inhibition of the COX-2 ameliorated the intestinal motility in the HS rats. Interestingly, we found in the present study that the COX-2 positive cells in intestine of rat after HS mainly were resident plasmacytes, infiltrating leukocytes and part of myenteric neurons which were located in lamina propria and submucosa. These distributions and cell types of COX-2 positive cells were remarkably different from that found in the aforementioned studies. These results suggest that there are different mechanisms by which the enhanced activation of COX-2 exacerbates the intestinal motility in different pathological states, such as HS vs. other kind of injuries that lead to intestinal dysmotility. Therefore, the precise mechanism underlying the COX-2 mediates intestinal dysmotility induced by HS still need to be determined.

COX-2 catalyzes arachidonic acid into a number of bioactive PGs such as TX $\mathrm{A}_{2}, \mathrm{PG} \mathrm{E}_{2}, \mathrm{PG} \mathrm{F}_{2 \alpha}$ and PG $\mathrm{I}_{2}{ }^{3}$. Out of these PGs, $\mathrm{PG} \mathrm{E}_{2}$ has been shown to be a critical factor for regulating intestinal motility. The receptors of $\mathrm{PG} \mathrm{E}_{2}$ are classified into four subtypes including $\mathrm{EP}_{1}, \mathrm{EP}_{2}, \mathrm{EP}_{3}$ and $\mathrm{EP}_{4} \mathrm{Shi}^{12}$ reported that $\mathrm{PG} \mathrm{E}_{2}$ derived from inducible COX-2 in bowel obstruction conditions negatively regulates motility function of gut via receptors of $\mathrm{EP}_{3}$ and $\mathrm{EP}_{4}$. Gonzalo ${ }^{15}$ demonstrated that $\mathrm{PG} \mathrm{E}_{2}$ decreases the contractile response of intestinal muscle strips in organ bath prepared from normal rabbits. In the present study, we found that contents of $P G E_{2}$ in intestinal tissues of HS rats were significantly increased while there were no changes in contents of TX $A_{2}, P G F_{2 a}$ and $P G I_{2}$. These results indicate that $P G E_{2}$, as one of important signal molecules of COX-2, mediates inteatinal dysmotility after HS. Recently, Tajima ${ }^{16}$ reported that $\mathrm{PG} \mathrm{E}_{2}$ acting on $\mathrm{EP}_{2}$ and $\mathrm{EP}_{4}$ receptors to upregulate $\mathrm{iNOS} / \mathrm{NO}$ in intestinal muscularis macrophages of mice insulted by endotoxemia, which in turn suppresses intestinal motility through a cAMP/ERK signal pathway. Previous studies ${ }^{10,11}$ also confirmed that inducible iNOS/ $\mathrm{NO}$ is involved in the development of intestinal dysmotility after HS. Therefore, it can be speculated that HS enhances the COX2 activity and $\mathrm{PG} \mathrm{E}_{2}$ production that exacerbate the intestinal motility via the inducible iNOS/NO pathway.

All of four $\mathrm{PG} \mathrm{E}_{2}$ receptor subtypes have been identified in rat colonic smooth muscle cell layer, and endogenous $\mathrm{PG} \mathrm{E}_{2}$ modulates physiological function mainly via $\mathrm{EP}_{1}$ and $\mathrm{EP}_{3}$ subtypes. The expression of $\mathrm{EP}_{2}$ and $\mathrm{EP}_{3}$ subtypes has been shown to increase rapidly in intestinal smooth muscle cells after mechanical stretch. However, $\mathrm{PG} \mathrm{E}_{2}$ produced by the overexpression of COX2 suppresses motility of intestinal muscle trips mainly through $\mathrm{EP}_{2}$ and $\mathrm{EP}_{4}$ subtypes in mechanical stretch conditions. Thus, EP receptor subtypes and signaling pathways that are responsible for the intestinal dysmotility in the episode of HS are warrant in the future study.

The intestinal dysmotility induced by HS involves COX2/PG $\mathrm{E}_{2}$ mechanism. Given the beneficial roles of COX-2 inhibition in amelioration of intestinal motility, further understanding the signal transduction through which $\mathrm{COX}-2 / \mathrm{PG} \mathrm{E}_{2}$ suppresses intestinal motility may help to develop more safe and selective therapies for prevention and treatment of intestinal dysmotility under HS related conditions.

\section{Conclusions}

Hemorrhagic shock increases the inducible expression of COX-2 in intestinal tissues, which, in turn, enhances the production of $\mathrm{PG} \mathrm{E}_{2}$. Therefore, a large amount of $\mathrm{PG} \mathrm{E}_{2}$ suppresses intestinal motility. These findings indicate that the enhanced COX-2/ $\mathrm{PG} \mathrm{E}_{2}$ involves in the HS-induced intestinal dysmotility. 


\section{References}

1. Fishman JE, Levy G, Alli V, Sheth S, Lu Q, Deitch EA. Oxidative modification of the intestinal mucus layer is a critical but unrecognized component of trauma hemorrhagic shock-induced gut barrier failure. Am J Physiol Gastrointest Liver Physiol. 2013 Jan;304(1):G57-63. doi: 10.1152/ajpgi.00170.2012.

2. Tiesi G, Reino D, Mason L, Palange D, Tomaio JN, Deitch EA. Early Trauma-hemorrhage-induced splenic and thymic apoptosis is gut-mediated and toll-like receptor 4-dependent. Shock. 2013 Jun;39(6):507-13. doi: 10.1097/SHK.0b013e318293d020.

3. Ruan YC,ZhouW, ChanHC. Regulation of smooth muscle contraction by theepithelium:role of prostaglandins. Physiology (Bethesda). 2011 Jun;26(3):156-70. doi: 10.1152/physiol.00036.2010.

4. Fredenburgh LE, Velandia MMS, Ma J, Olszak T, Cernadas M, Englert JA, Chung SW, Liu X, Begay C, Padera RF, Blumberg RS, Walsh SR, Baron RM, Perrella MA. Cyclooxygenase-2 deficiency leads to intestinal barrier dysfunction and increased mortality during polymicrobial sepsis. J Immunol. 2011 Nov;187(10):5255-67. doi: 10.4049/jimmunol.1101186.

5. Makar KW, Poole EM, Resler AJ, Seufert B, Curtin K, Kleinstein SE, Duggan D, Kulmacz RJ, Hsu L, Whitton J, Carlson CS, Rimorin CF, Caan BJ, Baron JA, Potter JD, Slattery ML, Ulrich CM. COX-1 (PTGS1) and COX-2 (PTGS2) polymorphisms, NSAID interactions, and risk of colon and rectal cancers in two independent populations. Cancer Causes Control. 2013 Dec;24(12):2059-75. doi: 10.1007/ s10552-013-0282-1.

6. Kreiss C, Birder L, Kiss S, VanBibber M, Bauer A. COX-2 dependent inflammation increases spinal Fos expression during rodent postoperative ileus. Gut. 2003 Apr;52(4):527-34. doi: 10.1136/gut.52.4.527.

7. Lin YM, Li F, Shi XZ. Mechano - transcription of COX - 2 is a common response to lumen dilation of the rat gastrointestinal tract. Neurogastroenterol Motil. 2012 Jul;24(7):670-7, e295-6. doi: 10.1111/j.1365-2982.2012.01918.x.

8. Gonzalo S, Grasa L, Fagundes DS, Arruebo MP, Plaza MA, Murillo MD. Intestinal effects of lipopolysaccharide in rabbit are mediated by cyclooxygenase- 2 through $\mathrm{p} 38$ mitogen activated protein kinase. Eur J Pharmacol. 2010 Dec;648(1-3):171-8. doi: 10.1016/j. ejphar.2010.08.041

9. Gonzalo S, Grasa L, Arruebo MP, Plaza MA, Murillo MD. Inhibition of p38 MAPK improves intestinal disturbances and oxidative stress induced in a rabbit endotoxemia model. Neurogastroenterol Motil. 2010 May;22(5):564-72, e123. doi: 10.1111/j.13652982.2009.01439.x.

10. Zhang YP, Wang XR, Zhao XQ, Qiao HX. The role of nitric oxide on the dysfunction of intestinal motility in rats subjected to hemorrhagic shock. Chinese Critical Care Med. 2013 Sep;25(9):533-6. doi: 10.3760/cma.j.issn.2095-4352.2013.09.006.

11. Hierholzer C1, Kalff JC, Billiar TR, Bauer AJ, Tweardy DJ, Harbrecht BG. Induced nitric oxide promotes intestinal inflammation following hemorrhagic shock. Am J Physiol Gastrointest Liver Physiol. 2004 Feb;286(2):G225-33. doi: 10.1152/ajpgi.00447.2002.

12. Shi XZ, Lin YM, Powell DW, Sarna SK. Pathophysiology of motility dysfunction in bowel obstruction: role of stretch-induced COX-2. Am J Physiol Gastrointest Liver Physiol. 2011 Jan;300(1):G99-108. doi: 10.1152/ajpgi.00379.2010.

13. Schwarz NT, Kalff JC, Turler A, Engel BM, Watkins SC, Billiar TR, Bauer AJ. Prostanoid production via COX-2 as a causative mechanism of rodent postoperative ileus. Gastroenterology. 2001 Dec;121(6):1354-71. doi: 10.1053/gast.2001.29605.

14. Fukata M, Chen A, Klepper A, Krishnareddy S, Vamadevan AS, Thomas LS, Xu R, Inoue H, Arditi M, Dannenberg AJ, Abreu MT.
Cox-2 is regulated by Toll-like receptor-4 (TLR4) signaling: role in proliferation and apoptosis in the intestine. Gastroenterology. 2006 Sep;131(3):862-77. doi: 10.1053/j. gastro.2006.06.017.

15. Gonzalo S, Grasa L, Arruebo M, Plaza M, Murillo M. Extracellular signal - regulated kinase (ERK) is involved in LPS - induced disturbances in intestinal motility. Neurogastroenterol Motil. 2011 Feb;23(2):e80-90. doi: 10.1111/j.1365-2982.2010.01632.x.

16. Tajima T, Murata T, Aritake K, Urade Y, Michishita M, Matsuoka T, Narumiya S, Ozaki H, Hori M. EP2 and EP4 receptors on muscularis resident macrophages mediate LPS-induced intestinal dysmotility via iNOS upregulation through cAMP/ERK signals. Am J Physiol Gastrointest Liver Physiol. 2012 Mar;302(5):G524-34. doi: 10.1152/ajpgi.00264.2011.

\section{Correspondence:}

Yu-Ping Zhang

Institute of Microcirculation, Hebei North University

11 Diamond South Road, Zhangjiakou

Hebei province, China, 075000

Phone: (86)0313-4029356

zhangeping@sina.com

Received: Aug 08, 2015

Review: Oct 10, 2015

Accepted: Nov 12, 2015

Conflict of interest: none.

Financial sources: Youth Foundation of Hebei Educational Committee (Q2012099).

${ }^{1}$ Research performed at Institute of Microcirculation, Hebei North University, Zhangjiakou Hebei, China. 